\title{
Sobre la democracia en el ámbito internacional *
}

\author{
ELENA GARCÍA GUITIÁN \\ Universidad Autónoma de Madrid
}

Resumen. Las transformaciones generadas por los procesos agrupados bajo la etiqueta de la globalización unidas a la desaparición del modelo de orden mundial establecido durante la Guerra Fría han hecho proliferar propuestas normativas que plantean la posibilidad y conveniencia de democratizar las relaciones en el ámbito internacional. Sin embargo, no está claro cómo puede y debe llevarse a cabo ese proceso, ya que la democracia está pensada como forma de gobierno que presupone una base territorial y un demos definido. Por ello, la aplicación de sus principios e instituciones al ámbito de las relaciones en la esfera internacional no puede hacerse sin más, sino que exige la adaptación de sus categorías al nuevo medio. Y una de las cuestiones que presenta más complejidad es la de la estructuración de la representación política.
Abstract. Changes originated by the complex dynamics labeled as globalization in the context of the end of Cold War world order have increased the number of normative proposals that focus on the possibility and convenience of democratizing the international sphere. Nevertheless, we still lack a clear understanding about how this process should and could take place. Democracy has always been thought as a form of government that presupposes some well defined territorial basis and demos. That is the reason why we should not try just to apply its principles and institutions to the international order, but to propose functional equivalents. And one of the most complex questions we have to deal with is the way to restructure political representation.

\section{El proyecto democrático en el nuevo contexto internacional}

Los diferentes procesos encuadrados bajo la etiqueta de la globalización han dejado al descubierto la creciente interconexión que existe entre política doméstica e internacional. Al analizar la repercusión de las transformaciones que están teniendo lugar desde la perspectiva de los Estados, se levanta la voz de alarma porque, a pesar de la diversidad de diagnósticos ofrecidos sobre las consecuencias y el alcance de dicha globalización, sí parece que hay acuerdo a la hora de concluir que está afectando a la autonomía de los Estados, a su eficacia, y también al funcionamiento democrático de sus instituciones.

* Este trabajo forma parte de la investigación realizada dentro del proyecto de I+D, Democracia: más allá de las fronteras, BSO2000-0111, financiado por la DGI del Ministerio de Ciencia y Tecnología. 
Como señala Beck (1998), la globalización no es un fenómeno totalmente nuevo, sus efectos son variados y multidimensionales, y no repercuten por igual en todos lados, pero sus conexiones han aumentado y se han hecho más profundas, y lo que sí parece ser una novedad es el aumento de la autopercepción de esa transnacionalidad. Sin embargo, aunque estos cambios sustantivos y cualitativos no implicarían, por lo menos a corto plazo, la desaparición total de los Estados, sí han comenzado a afectar a su carácter, funcionamiento y fuentes de legitimidad. Porque una de las consecuencias más señaladas de estos procesos sería propiciar la desterritorialización del poder, lo que supone una importante transformación de la organización espacial de las actividades humanas, de forma que lo local comienza a tener repercusiones inmediatas en ámbitos remotos, se facilita la multiplicación y superposición de identidades y lealtades y, lo más importante, aparece en escena una «sociedad mundial» que no se corresponde con ningún Estado. En opinión de Held (1997), son muchas las causas que generan este efecto, y su principal efecto es poner de relieve la contradicción existente entre el dominio formal de la actividad política que los Estados nacionales reclaman para sí y las prácticas y estructuras reales del sistema político y económico en todos los niveles. Y esto, a su vez, acaba con la idea de una «comunidad nacional de destino» presupuesta en la política doméstica.

Naturalmente, estos cambios afectan de manera singular al sistema político democrático porque la ruptura de la identificación territorial del demos como colectividad que decide de forma autónoma su destino supone el resquebrajamiento de la base sobre la que se construye la concepción tradicional de la democracia. Pero hay otros desarrollos que repercuten en su funcionamiento. Así, aunque podamos considerar positiva la generalización de la percepción de que hay problemas colectivos que sólo se pueden resolver cooperativamente, poniendo de relieve la estrecha conexión existente entre lo doméstico y lo exterior, la proliferación anárquica de regímenes y organizaciones internacionales creadas para organizar las áreas afectadas plantea problemas de transformación de los marcos legales, representatividad y control que pueden ser poco aceptables desde una perspectiva democrática. Otro de los efectos, esta vez de la denominada «globalización cultural», sería la corrosión de la base identitaria que está detrás de la delimitación de los demos, dando lugar en muchos casos a su sustitución por otras más locales y exigentes, en muchos casos con terribles resultados. Y, sobre todo, la creciente internacionalización de las economías detrae a los gobiernos democráticos la posibilidad de utilizar las medidas económicas necesarias para adoptar muchas de las políticas demandadas por sus ciudadanos.

El diagnóstico de los efectos de la globalización sobre la democracia no es tan pesimista, sin embargo, cuando el tema se analiza desde la perspectiva del ámbito internacional, porque en él se mezclan tanto los elementos que promueven la democratización como los que la anulan. En este ámbito, aunque 
los actores principales siguen siendo los Estados, asistimos a la formación de lo que se ha denominado una «sociedad mundial» sin base territorial en la que tienen cabida también otro tipo de actores transnacionales y que está dando lugar de forma simultánea a dos fenómenos en cierta medida opuestos. Por un lado, en ese espacio los gobiernos democráticos de los Estados se ven cada vez más forzados a comportarse democráticamente (o a aparentar que lo hacen) en sus relaciones exteriores, y los no democráticos son presionados para que adopten los principios de legitimación democrática sobre la base de un derecho internacional que ya no se concibe sólo como regulador de las relaciones interestatales, sino que incorpora exigencias normativas más fuertes. Y a ello ha contribuido sin duda la progresiva implantación de lo que se ha venido a llamar el «régimen de los derechos humanos», promovido sin duda, además de por los Estados con regímenes democráticos, por instancias transnacionales. Pero, por otro lado, estos resultados no son producto de un gobierno mundial, sino de lo que se ha calificado (Rosenau, 1998) como un «sistema de gobernación sin gobierno». La esfera de las relaciones internacionales no puede concebirse como un ámbito de pura anarquía, sino que está ordenada por una estructura de mecanismos de control y diferentes equilibrios de poder. Y el problema es que esos mecanismos están en manos de organismos y organizaciones internacionales (los denominados «global players»: las ONG, OIG, etc., muchos de los cuales se consideran componentes de una emergente sociedad civil internacional) que no están sometidos a las exigencias impuestas por la democracia: funcionamiento democrático interno, deliberación de los afectados o sus representantes, rendición de cuentas, etc.

En este nuevo contexto mundial, no es de extrañar, pues, que una de las dimensiones de la teoría normativa en expansión sea la elaboración de modelos tanto acerca de la perenne cuestión de la mejor forma de abordar la democratización interna de los Estados como la de sus relaciones en el contexto internacional. Y no es que hasta ahora la teoría política se hubiera desinteresado por estas últimas y no hubiera sugerido propuestas normativas que inspiraran y sirvieran de estándar para evaluar su funcionamiento, como prueba el renovado interés por el proyecto kantiano de paz perpetua. También se señala (Archibugi, 1998) que detrás de determinados regímenes de gran trascendencia histórica (tales como los conformados por la Paz de Westfalia de 1648 o la Paz de Utrecht de 1712), se hallan las tesis de teóricos políticos relevantes (Grocio, Abbé de Saint Pierre). Lo que diferenciaría hoy la perspectiva normativa es la presencia de una actitud mucho más optimista sobre las posibilidades de influencia de ideales y principios en la regulación de la esfera de las relaciones internacionales, a lo que sin duda han contribuido los fenómenos a los que nos estamos refiriendo: el fin del orden mundial instaurado tras la Guerra Fría, la extensión progresiva del denominado régimen de derechos humanos, la proliferación de organismos de cooperación internacionales, la monopolización de la legitimidad por parte de los regímenes democráticos, etc. 
Aunque los proyectos propuestos están siendo muy distintos, la idea estrella que subyace a la mayoría de ellos es la pretensión de «democratizar» el ámbito internacional, tanto en lo que atañe a las relaciones interestatales como al funcionamiento de ese régimen de gobernación mundial. Porque la alternativa parece ser acabar en una especie de neomedievalismo, concebido como un sistema caótico de autoridades superpuestas y lealtades divididas y que afectaría seriamente a la idea de consentimiento, control y rendición de cuentas democrática.

Pero no nos equivoquemos, porque esta visión positiva de la necesidad y deseabilidad de democratización del ámbito internacional no está absolutamente extendida. Los defensores de un enfoque realista de la política, sobre todo en lo concerniente a la esfera internacional, son escépticos respecto a la posibilidad de superar el modelo tradicional basado en el reconocimiento de la igualdad de unos Estados como únicos sujetos de acción, que se rigen en sus relaciones por el interés particular, y que se mueven en un contexto de equilibrios de poderes desiguales. Porque además consideran que el régimen interno de un Estado y los principios que propugna no influyen en su política exterior (por lo que el aumento del número de Estados democráticos no se traduciría en la democratización automática del ámbito internacional).

Junto a estos argumentos clásicos, existe también otro tipo de recelos que provienen de la percepción de problemas muy distintos. Algunos de ellos son los planteados por los que sospechan de la presunta universalidad del sistema democrático y ponen en duda su papel exclusivo como fuente de legitimidad de cualquier sistema político (por ejemplo, Zolo, 2000). En este sentido, estos autores no sólo consideran que no debería imponerse la exigencia de que todos los Estados adopten la forma democrática, sino que están convencidos de que no tiene sentido exportar el modelo democrático al ámbito internacional, en el que no tendría razón de ser. Desde una perspectiva no normativa sino funcionalista (Rosenau, 1998), se señala que el intento de instaurar una estructura jerárquica (que se presenta como inevitable en el proyecto de construcción de un orden democrático) que ordene las múltiples dimensiones que caracterizan la gobernación mundial está destinada al fracaso, porque el mundo está demasiado desagregado para las grandes lógicas que persiguen algún grado de coherencia global. Además, la tendencia resultante de la nuevas transformaciones generadas por la globalización sería precisamente incrementar, no disminuir, el grado de anarquía global. Por ello, el objetivo de cualquier nuevo orden mundial debería centrase en la prevención y resolución de los conflictos más graves y no en el diseño de una estructura de gobierno mundial.

Todos los teóricos adscritos a este tipo de enfoques críticos aplaudirían sin duda la implantación de un orden internacional más adecuado, que es siempre necesario, pero los reparos se situarían en la creencia en que ese orden tenga que ser necesariamente democrático, por lo menos concebido según el modelo aplicable a los Estados. Y en esta última objeción coincidirían 
con las nuevas utopías, en las que se augura que la fuerza de las cosas, los nuevos desarrollos favorecidos por la globalización, generarán por sí solos un nuevo orden presuntamente democrático (de base individualista, descentralizado, apoyado en tecnologías que permiten la participación política directa), pero que supera la concepción tradicional y no estará inspirado en ningún modelo conscientemente articulado.

Estos argumentos críticos no tienen, sin embargo, igual relevancia para todos los modelos normativos propuestos e inmediatamente suscitan la fundamental cuestión de detallar qué tipo de democratización es la propugnada. Y para plantear esta cuestión ni siquiera tenemos que entrar en el espinoso tema de la multiplicidad de modelos de democracia existente (liberales, republicanos, etc.), sino empezar un paso antes, preguntándonos qué tipo de democratización sería posible y/o deseable en el nuevo orden mundial y su relación con las democracias estatales. Porque una cosa es pensar que dicha democratización no es factible y otra que no es deseable.

\section{El régimen de derechos humanos y la democracia}

En la actualidad parece contemplarse con optimismo la supuesta existencia de condiciones que permiten y prácticamente conducen a la democratización, tanto de los regímenes políticos de los Estados como de la sociedad internacional, apoyadas sobre todo en lo que se considera la imparable extensión del denominado «régimen de derechos humanos». Los autores que celebran este desarrollo señalan (Beetham, 1998) que las concepciones más o menos amplias de derechos humanos ${ }^{1}$ componen una filosofía y un sistema de derecho internacional que constituye un componente fundamental de legitimación de una emergente sociedad civil internacional. A estos derechos, a diferencia de lo que parece ocurre con la democracia, se les atribuye un carácter universalista y global en su alcance. Y su implantación se está llevando a cabo por una red de instituciones formales e informales. Las primeras, entre las que ocupa un lugar destacado la ONU, complementada por otras organizaciones regionales, han propiciado el establecimiento de una jurisdicción independiente expresada en cartas y convenciones internacionales y la creación de comités de expertos para supervisar su cumplimiento, que pueden intentar hacer efectivo utilizando ciertos instrumentos (limitados) de presión. Junto a ellas se han desarrollado otras instituciones de tipo informal (ONGs) que también juegan un papel impulsor y creador de legislación internacional, recogen pruebas de abusos y proporcionan información alternativa, además de apoyar causas particulares que afectan a individuos o grupos en las instancias internacionales.

\footnotetext{
${ }^{1}$ En este punto hay serias divergencias sobre qué derechos entran en la categoría de derechos humanos. Así, mientras unos autores entienden que se trata de un mínimo, otros los amplían incluyendo derechos sociales, económicos, políticos y culturales, como es el caso del propio Beetham.
} 
La proliferación de este tipo de organizaciones ha hecho que se dé por sentado que ya estamos ante una sociedad civil internacional que despliega su actividad en el ámbito global y media entre los actores en este nivel y el local. Y lo que es destacable es precisamente que obtienen su legitimidad de ese régimen de derechos humanos, y no de su funcionamiento interno democrático.

Dicho esto, una de las preguntas importantes que hay que plantearse es cuál es la relación de este régimen con el proyecto democrático, tanto en el ámbito interno de los Estados como en el internacional, si es que tiene alguna. Beetham (1998:66), por ejemplo, opina que existen desarrollos que ligan el régimen de derechos humanos y el proyecto de democracia cosmopolita. Piensa que el primero proporciona el contenido mínimo para fundamentar una ciudadanía global democrática y que las instituciones y los procedimientos que se utilizan para promoverlo, en ausencia de una autorización electoral o rendición de cuentas, constituyen un régimen representativo gracias al papel que desempeña la Asamblea de las Naciones Unidas, la procedencia variada de los expertos que trabajan para ella, que garantizan la pluralidad, y el hecho de que los procedimientos de esta institución sean públicos y estén siendo supervisados por las ONGs. Otra de sus consecuencias, que inciden en su presunto carácter democrático, sería haber facilitado la creación de una elite cosmopolita que se compromete con las luchas locales y las hace globales. Y, por último, este autor señala que a medida que se incrementa la intervención en algunas áreas invocando los derechos humanos se suscita la necesidad de que esa intervención se extienda a otras que están conectadas, y la asunción de nuevos poderes acentuaría el «déficit democrático», que crearía nuevas exigencias de rendición de cuentas. El punto más débil de todo este sistema sería el problema de la imposición o la incapacidad para forzar su cumplimiento, pero la evolución progresiva que parece haber experimentado en la práctica ofrecería razones para el optimismo.

La conclusión de Beetham, por tanto, es que este régimen de derechos humanos haría surgir algo necesario para la democratización: ciertas instituciones y una sociedad civil mundial. Conclusión compartida por autores como Held (1997), que insiste en que ya hay una base sobre la que es posible proceder a la democratización: incremento de movimientos sociales con objetivos regionales y globales; extensión de la protección de los derechos humanos; y proliferación de las organizaciones e instituciones internacionales. Porque la creación de una comunidad cosmopolita no requeriría una integración política y cultural en forma de un consenso amplio sobre normas y valores, pero sí el reconocimiento de la diferencia y el compromiso con la democracia.

Pero aún hay más. Algunos analistas (Crawford y Marks, 1998:78) opinan que el proceso de democratización impulsado por el régimen de los derechos humanos está en una etapa más avanzada, pues aunque los acuerdos internacionales y especialmente la Carta de las Naciones Unidas no asumen directamente la exigencia de democracia, incorporan algunas obligaciones referidas 
a ciertos elementos constitutivos de ella, sobre todo la necesidad de que se celebren elecciones y que se haga efectivo el derecho de participación política. Parecería así que se está produciendo de verdad el reconocimiento formal de la democracia como la única forma de gobierno legítima cuya asunción generalizada conducirá a la paz mundial. Concebido de este modo, el modelo de democracia a implantar sería mínimalista, pues se satisface formalmente con la mera celebración de elecciones periódicas; pero el propio régimen de derechos humanos impulsado por las organizaciones internacionales incluye otras exigencias que forman parte de los elementos que definen las democracias modernas: consagración de libertades de expresión, asociación y reunión, principio de legalidad, separación de poderes, etc., que subrayan la necesidad de que se vaya más allá de la concepción electoralista profundizando en otros contenidos de la democracia como la existencia de mecanismos efectivos de control del poder, libertad de información o mayores ámbitos de participación.

El resultado de la extensión de este régimen de derechos humanos, entonces, habría sido, en primer lugar, otorgar una creciente legitimidad a la idea democrática en distintas tradiciones y el aumento efectivo (no sin regresiones) del número de regímenes que ahora son considerados democráticos. Pero tendríamos que subrayar también que el modelo que se ha extendido es un modelo formal de mínimos identificado con celebración de elecciones competitivas, existencia de ciertas libertades, algún grado de pluralismo político y fuentes de información alternativas, pero de dudosa calidad desde el punto de vista sustantivo.

En relación con este tema, tenemos que tener en cuenta que la evaluación de este proceso y su repercusión desde el punto de vista democrático no es unánime. Todavía son muchas las voces que cuestionan el propio contenido del régimen de los derechos humanos por considerarlo etnocentrista, un instrumento en manos de las superpotencias para garantizar su hegemonía. Zolo (2000), por ejemplo, desacredita a la denominada ética internacional como fundamentadora de un régimen cosmopolita por asumir sin más que la doctrina de los derechos humanos es universal y racional, y que éstos son derechos positivos vinculantes que no pueden ser garantizados por los Estados. La consecuencia de esta asunción sería hacer sujetos a los individuos en el orden jurídico internacional creando una especie de ciudadanía cosmopolita y una idea ética de la comunidad internacional. Por el contrario, este autor piensa que los derechos humanos así concebidos son los que en el orden mundial aparecido con posterioridad a la Guerra del Golfo fundamentan el derecho de injerencia humanitaria y la idea de un constitucionalismo global (según el modelo de Estado de derecho europeo). Pero, en su opinión, no son más que derechos occidentales, carentes de fundamento racional, y un verdadero instrumento de occidentalización, ya que su control e imposición, tal como aparece ahora organizado, está en manos de las superpotencias.

Junto a este tipo de argumentos que cuestionan el punto de partida, la legitimidad del propio régimen de derechos humanos, cabe encontrar otras 
objeciones dirigidas a su presunta conexión con la promoción de la democracia en el ámbito mundial. Porque si bien plantea exigencias internas a los Estados para que hagan respetar los derechos en su ámbito doméstico y ciertos elementos democráticos, no está claro que profundice en la organización democrática del ámbito mundial, donde parece limitarse a consagrar un precario «rule of law» de mínimos. Porque resulta un tanto optimista pensar que el funcionamiento de las instituciones internacionales es democrático por contar con expertos de diversos orígenes y estar siendo supervisadas por ONGs. En este sentido, son muchos los teóricos (por ejemplo, Bobbio, 1998) que consideran inevitable la conexión entre democracia doméstica y comportamiento pacífico y democrático en el ámbito internacional, por lo que están convencidos de que la democratización de la sociedad internacional se conseguirá consiguiendo la de los Estados. Pero parece que la realidad insiste tozudamente en negar dicha conexión, pues suele existir (Archibugi, 1998) una falta clara de coherencia entre los principios de organización interna y la política exterior de un Estado, confirmada por los datos empíricos que demuestran que las democracias no han sido más pacíficas que las autocracias, y que lo que no ha habido son guerras entre países democráticos, de ahí que se presuma que si todos los países fueran democráticos se acabarían los grandes conflictos. ¿Cómo debe abordarse entonces el tema de la relación entre democracia interna y del orden internacional? O mejor, ¿cómo debería ordenarse dicho orden y cuál sería su relación con los Estados democráticos o no?

\section{Los proyectos de democratización de la nueva sociedad internacional}

Lo único que parece claro desde la perspectiva de la teoría democrática es la necesidad de abordar conjuntamente ambos temas, el de la democratización doméstica e internacional, y con lo que nos encontramos es con una amplia diversidad de propuestas sobre cuál deba ser su relación. Por ello, aunque las categorías simplifican los rasgos peculiares de cada una de esas propuestas individuales, vamos a centrarnos en la descripción de lo que consideramos son cuatro enfoques diferentes (sin que intenten ser exhaustivos e incorporar todos los puntos de vista que sobre el tema existen, sino más bien ilustrativos de las diferentes posiciones). El primero se caracterizaría por insistir más en un cierto desarrollo de controles de los comportamientos en el ámbito internacional, que podría identificarse con un «rule of law» de mínimos (en diferentes versiones, más o menos exigentes), pero que respetaría la pluralidad e independencia máxima de los Estados, que seguirían siendo los actores protagonistas en el ámbito internacional. Desde este punto de vista, la democracia no tendría un especial estatus ni en el ámbito doméstico ni en el internacional, pues lo exigible sería sólo un comportamiento acorde con unas normas que garantizaran una convivencia respetuosa y pacífica. El segundo enfoque seguiría considerando a los Estados los actores principales en el ámbito internacional, 
pero resaltaría la importancia fundamental del proyecto democrático doméstico, y depositaría en la unión de los Estados democráticos la esperanza de alcanzar la paz e incluso de establecer ciertos principios de justicia en el orden internacional. El tercero, compondría un modelo fuerte de democracia en tres niveles: doméstico, relaciones interestatales y nuevo orden mundial cosmopolita. Y el cuarto enfoque sería el cajón de sastre que recogería las propuestas de nuevas formas de democracia que insistirían en el protagonismo de individuos liberados de los ámbitos de sujeción estatales y organizados por medio de las nuevas tecnologías. Lo que se enfatiza desde esta última perspectiva son los ideales democráticos de participación ciudadana directa (ya como componentes de una sociedad civil global), el acceso a una información plural y la descentralización institucional, todo ello en un contexto de debilitamiento natural del poder.

Pero veamos algunas de estas propuestas con más detalle.

Modelo 1: En la versión que presenta, por ejemplo, Zolo (2000), el punto de partida es la constatación de que el cosmopolitismo contemporáneo interpreta mal los procesos de globalización presentándolos como una tendencia hacia la sustitución del «sistema de Estados» y la formación de una crecientemente homogénea «sociedad civil global». En su opinión, esta perspectiva subestima enormemente la influencia de factores económicos y financieros en la aparición de los conflictos internacionales, que son además los que dan lugar a las enormes diferencias existentes en el desarrollo de los distintos países. Y tiende a confundir la globalización con «occidentalización», proceso que origina nuevos conflictos y un gran desarraigo en lugar de una creciente integración. Frente a lo que define como la visión cosmopolita, Zolo plantea recuperar la ideología federalista (que no hay que confundir con la teoría del Estado federal moderno) como base del nuevo orden mundial, que se apoya en la creencia en que la mejor garantía es la diseminación del poder con objeto de respetar el pluralismo. Así, el nuevo orden mundial seguirá basándose en el sistema de Estados, pero forzaría a una mayor cooperación entre sus componentes. La única autoridad mundial justificada, por tanto, sería la que permitiría (siguiendo el principio de subsidiariedad de la perspectiva federalista) instaurar un «orden político mínimo», sin intentar alcanzar el «orden político óptimo» que suele incorporar objetivos tan amplios como la paz estable, la justicia distributiva, la definición y garantía de los derechos, la protección ecológica o el equilibrio económico. Y la base del funcionamiento de este sistema sería una filosofía de intervencionismo mínimo, apoyada en una red de instituciones internacionales que contribuyeran a aumentar las relaciones interculturales, a reforzar las identidades particulares, y a contener la occidentalización, junto a otras de carácter «débil» encargadas de la vigilancia de conflictos potenciales, del fomento de la interacción entre partes en conflicto, de la organización de una diplomacia preventiva y que contribuyan al establecimiento de la paz y al control de armamentos, pero que nunca se com- 
prometan en intervenciones armadas. Estas instituciones adoptarían una forma de organización descentralizada, y deberían contar con una financiación amplia que garantice su independencia de las superpotencias.

En este modelo la preocupación por la democracia está expresamente descartada, pues no se considera el único sistema de gobierno legítimo, por lo que no tendría sentido promover su imposición o extensión generalizada. Tampoco se suscitarían problemas de representación democrática en el ámbito internacional, porque lo único que se propugna es establecer un mínimo «rule of law» en cuyo diseño tomen parte, eso sí, todos los Estados, únicos sujetos del ámbito internacional, en condiciones de igualdad. El orden más justo estaría orientado a atenuar el control de las superpotencias occidentales, dando una mayor voz a los Estados más débiles en todas las instituciones y organizaciones internacionales y respetando su pluralidad.

Modelo 2: Los enfoques aquí agrupados se caracterizarían, igual que en el primer modelo, por apoyarse principalmente en un orden internacional de Estados, si bien propugnan la construcción de una estructura mucho más integrada de funcionamiento común, pero se distinguirían por incorporar una evaluación positiva de la democracia. La base para conseguir alcanzar un orden mundial pacífico y justo sería así la unión de los Estados democráticos con objeto de imponer progresivamente sus valores en la organización del orden mundial.

Una de las versiones más importantes sería la clásica kantiana, aunque las interpretaciones sobre su contenido exacto son variadas. Kant establece tres tipos de constituciones jurídicas: el derecho político de los hombres en un pueblo (ius civitatis); el derecho de gentes o de los Estados en sus relaciones mutuas (ius gentium); y los derechos de la humanidad como ciudadanos de un Estado universal de todos los hombres (ius cosmopoliticum). El primero es producto de los Estados legítimos, que sólo pueden ser los gobernados bajo la forma republicana. El segundo debería ser creado por una sociedad de naciones o una federación de Estados libres, que no reclamaría ningún poder del Estado, sino simplemente se ocuparía de mantener y asegurar la libertad de un Estado en sí mismo y también la de los demás Estados federados, sin que éstos hubieran de someterse por ello a leyes políticas y a una coacción legal. Pero Kant también indica que el derecho de gentes está formado por un conjunto de leyes públicas coactivas que reducen la libertad de los Estados, constituyendo un Estado de naciones. Y este punto da lugar a cierta confusión. Parece concluirse que el modelo ideal para alcanzar la paz perpetua exigiría que los gobiernos bien ordenados, las repúblicas, crearan un Estado de naciones (civitas gentium) que impusiera leyes públicas coactivas sobre los Estados, y sólo en el caso de que esto no fuera posible, se debería intentar formar una federación de Estados republicanos que garantizaran la paz y la aplicación del ius gentium (o derecho de los Estados en sus relaciones mutuas). Y en esta interpretación, el ius cosmopoliticum, como ciudadanos de un Estado uni- 
versal de todos los hombres, sólo regularía las relaciones de hospitalidad (porque Kant rechaza expresamente que sea deseable crear un Estado mundial). Sin embargo, ésta no es una versión aceptada por todos los estudiosos kantianos, ya que algunos identifican la creación del Estado de naciones (considerándolo una especie de Estado mundial) con la base institucional para el desarrollo del derecho cosmopolita.

Sin entrar a abordar este espinoso tema, simplemente destacamos que la base del nuevo orden, en este modelo, serían los Estados republicanos (democráticos), que constituirían un alianza que daría lugar a un sistema institucional basado en los principios que defienden.

La versión actualiza del modelo kantiano, pero que supera sus pretensiones, es la de Rawls (1997). Su trabajo The law of peoples defiende una concepción política del derecho y la justicia que se aplica a los principios y normas de la ley y a la práctica internacional. En la sociedad de los pueblos se admiten todas las sociedades «bien ordenadas», sean liberales (democráticas) o no, que son las que respetan un mínimo de derechos humanos, no son expansionistas y tienen un sistema legal que satisface ciertas condiciones de legitimidad a ojos de sus propios ciudadanos. Los principios de justicia que regirán la sociedad internacional se adoptarían después de decidir los domésticos, pero partiendo de la aceptación de la base estatal y, por tanto, del concepto de soberanía con sus implicaciones: el reconocimiento del derecho de ir a la guerra por intereses prudenciales y el derecho a la no injerencia externa en sus asuntos internos, aunque el derecho de gentes introduce ciertas restricciones. Lo que sí es conveniente destacar es que este derecho de gentes no es idéntico al derecho internacional, que es un sistema jurídico incompleto y sin sanción, pues incorpora una serie de principios de derecho, justicia y bien común que aspiran a extender la idea de justicia liberal al derecho internacional y que servirán para evaluar dicho derecho.

En este modelo es en la posición original donde se deciden los principios que determinarán los criterios de justicia y las formas de cooperación entre los diferentes pueblos, pero sin que sea necesaria la creación de un Estado mundial. Rawls sigue, por tanto, a Kant al pensar que un gobierno mundial sería un despotismo global o un imperio frágil, y sólo apoyaría el establecimiento de determinadas instituciones gobernadas por el derecho de gentes con posibilidad de intervención.

No obstante, al observar los principios básicos de justicia propuestos en el ámbito internacional nos damos cuenta de que se centran sobre todo en las relaciones entre Estados (ius gentium) y no tanto en la elaboración o desarrollo de un derecho cosmopolita Tampoco, a diferencia del proyecto kantiano, se exige que los Estados sean repúblicas (o democracias) sino que respeten el mínimo de los derechos humanos, que establecen el estándar para determinar si una sociedad «está bien ordenada». En opinión de Rawls, los derechos humanos son una especie de derechos especiales de aplicación universal y no muy 
controvertidos. Son parte de un derecho de gentes razonable que especifica los límites de las instituciones domésticas exigidos por el derecho a todos los pueblos. Pero sí hay alusiones a la promoción de la democracia, cuya legitimidad parece presumirse en la definición de los regímenes liberales y en la evaluación de los que no lo son.

En la descripción de estas propuestas no está presente el discurso de la globalización. La perspectiva de la que parten es la visión clásica de que el ámbito internacional es sobre todo el ámbito de las relaciones entre Estados, y que el objetivo fundamental es instaurar en él la paz y establecer unos mínimos estándares de justicia. Desde el punto de vista institucional, el único problema de la representación lo constituye la presencia de los Estados en el establecimiento de los principios que van a regir sus relaciones, y que esas decisiones colectivas se adopten permitiendo su participación en igualdad de condiciones. Sin embargo, sólo lo estarían las sociedades «bien ordenadas», liberales o no, porque, a diferencia del modelo anterior, sí se defiende la especial legitimidad de determinados valores (los del gobierno republicano, los derechos humanos, ciertos principios liberales) que son los que deberían promoverse y finalmente implantarse en el ámbito mundial. Y la legitimidad de estos principios excluye a las sociedades jerárquicas de cualquier presencia, aunque sólo legitimaría una intervención directa en el caso de amenaza para los demás, dejando a otros mecanismos de presión la misión de ayudar a convencerlas a que acepten dichos principios.

Modelo 3: El proyecto más articulado representativo de este modelo es la democracia cosmopolita, propuesta popularizada y definida con detalle entre otros por Held (1997). Su objetivo principal sería la creación de una comunidad democrática que incluya pero a la vez supere los Estados democráticos. Y uno de los rasgos que lo caracterizan es insistir en que los ciudadanos, independientemente de donde se encuentren, tengan voz y estén representados en los asuntos mundiales de forma paralela y diferenciada a como lo están en sus propios Estados. Implica, además, una concepción sustantiva de democracia que supera la puramente procedimental.

Los cosmopolitas se toman la globalización en serio y piensan que está generando a un tiempo procesos contradictorios: extiende la legitimidad del régimen democrático, reduce por la fuerza de los hechos el carácter democrático de los regímenes que ya son democráticos, y favorece las posibilidades de democratización del ámbito internacional. Por ello consideran imprescindible contrarrestar el debilitamiento imparable de la soberanía de los Estados con el establecimiento de nuevas formas de autoridad política democráticamente legitimada.

Se trata de un proyecto que parte de la asunción de la especial legitimidad del gobierno democrático y de sus principios y que, por tanto, debe organizarse al mismo tiempo en los tres niveles ya destacados por Kant (Archibugi, 1998): 
a) La promoción de la democracia como forma de gobierno, no sólo formal sino sustantiva, en todos los Estados a través de ciertas formas de presión apoyadas en la legislación internacional.

b) La aplicación de la democracia a las relaciones entre Estados basada en el reconocimiento del principio de la igualdad estatal y el respeto a la soberanía. En este ámbito se favorecería el desarrollo de instituciones intergubernamentales en diferentes niveles para fomentar la cooperación y abordar problemas regionales. Y el principio de representación seguiría siendo el tradicional: un Estado, un voto.

c) Organización de una democracia global para tratar problemas globales. Aquí sí sería necesario articular nuevas y diferentes formas de representación, pues se reconoce el hecho de que algunos gobiernos siguen siendo autoritarios y entran en conflicto con la sociedad civil que deberían representar. Por ello se propone una representación política de los ciudadanos en lo que afecta a los problemas globales independiente de la que tienen en los asuntos domésticos.

Este tercer nivel se justifica en la idea de que la defensa de la democracia en el contexto actual hace imprescindible articular instituciones cosmopolitas que, en esferas bien delimitadas, se pongan por encima de los Estados. Estas instituciones se apoyarían en una concepción de ciudadanía global o mundial y podrían participar en la gestión de asuntos de repercusión internacional e interferir dentro de los Estados cuando se violen los derechos humanos. Y los defensores de este proyecto no han evitado proponer medidas concretas para ello: transformar algunas instituciones (ONU, UE...) para hacerlas más representativas y responsables, así como crear otras nuevas; promover la democratización de los Estados, y favorecer la participación de los agentes globales en instituciones de todo tipo.

Pero para ver de verdad el alcance del modelo debemos analizar bien el concepto de democracia del que parte, que, por lo menos en la versión más desarrollada de Held (1997), incorpora exigencias que desde luego no se consideran de forma generalizada intrínsecas a la idea de democracia. En opinión de este autor, el principio constituyente del proyecto de democracia liberal (no de otros modelos de democracia) es el principio de autonomía, porque es el elemento que une el núcleo del Estado moderno (que consagra el imperio de la ley, la igualdad legal y la protección de derechos) como sistema de poder limitado que se impone a todos por igual, y la democracia (legitimada en el consentimiento ciudadano), que se deriva de la idea de autodeterminación.

El objetivo de las autoridades sería entonces promover la autonomía, ideal regulativo de la vida pública. Sin embargo, la igualdad que exige este principio se ve amenazada en diferentes ámbitos de poder por la persistencia de estructuras de desigualdad, y para superarlas se hace imprescindible consagrar y proteger mediante estrategias diversas los distintos tipos de derechos: a la salud, sociales, culturales, cívicos, pacíficos, económicos y políticos. Y para 
conseguirlo, Held subraya que es necesario disponer de un modelo de participación en los asuntos públicos (porque en su opinión la participación en la deliberación determina el resultado de lo decidido).

No obstante, aunque en la modernidad los derechos casi siempre se consagraron dentro de las instituciones del Estado-nación, los cosmopolitas subrayan que en la actualidad éste se ve impedido por la acción de otras comunidades políticas y agentes que operan a través de sus fronteras para desempeñar adecuadamente esta función, por lo que para lograr consagrar la autonomía de sus ciudadanos deberá estar apoyado por una estructura legal internacional.

Held, a diferencia de otros autores, no piensa que la base de dicha estructura sean los derechos humanos, sino los derechos intrínsecos a la democracia (los derivados de las exigencias del principio de autonomía), por lo que deberían ser asumidos por los que la aceptan como régimen legítimo y deseable. Evitando muchas críticas, reconoce abiertamente que es posible aceptar la relatividad histórica y cultural de la democracia sin sacrificar la afirmación de que quien la asume como mejor forma de gobierno también debe comprometerse con todas las condiciones que incorpora. Y aquí es donde plantea el concepto de «derecho democrático cosmopolita», que pertenece a un dominio diferente del derecho de los Estados y de las leyes que vinculan a un Estado con otro (lo que constituiría la base del derecho internacional) y que debería incluir el goce de la autonomía y el respeto de sus restricciones necesarias. Así, en nombre de dicho principio hasta se justificaría la intervención política en la economía para introducir nuevas cláusulas dentro de las normas básicas que regulan el sistema de libre mercado, pero que en la actual situación sólo serían efectivas respaldadas por una legislación global.

De esta forma, la adhesión al principio de autonomía implicaría el deber de trabajar por el establecimiento de una comunidad internacional de Estados democráticos que se comprometen a respaldar el derecho público democrático dentro y fuera de sus fronteras: la comunidad democrática cosmopolita. Los Estados se reorganizarían y articularían bajo el marco del derecho democrático global y la aceptación de este derecho serviría para evaluar su legitimidad.

Desde un punto de vista organizativo, el sistema requiere un conjunto de instituciones que cuide la consolidación y aplicación general del derecho básico, y que podría estar compuesto por una amplia gama de centros autónomos de toma de decisiones sólo sujetos al cumplimiento de los requerimientos del derecho democrático (porque no se trata de crear un supra-Estado mundial ni nada parecido). Los Estados-nación serían uno de esos centros, pero habría otros: redes de Estados, entidades subnacionales, agencias transnacionales, etc. Se trataría de establecer un marco legal general, pero que se desarrollaría de forma descentralizada en diferentes niveles de soberanía: regional, nacional y local, con competencias distribuidas de acuerdo con el principio de subsidiariedad (característico de la ideología federalista). Y Held (1997:360) desciende a los detalles para hacer sus propuestas de reforma (unas a corto y 
otras a largo plazo): redefinición de las fronteras territoriales de los sistemas de rendición de cuentas a fin de que los temas que escapan a la potestad del Estado-nación se sometan al control democrático; reforma de la articulación de las instituciones políticas con los grupos, asociaciones y organizaciones de la economía y la sociedad civil nacional e internacional para integrarlas en el proceso democrático; desarrollo del derecho cosmopolita democrático en constituciones y tratados; creación de un poder ejecutivo y legislativo transnacional en los ámbitos regional y global, en concreto una Asamblea general de los Estados con poderes ejecutivos y una Asamblea de los pueblos democráticos, apoyados por una fuerza militar y tribunales internacionales; utilización del referéndum para decidir temas concretos; incremento del escrutinio público de las organizaciones internacionales, todo ello complementado con la recuperación de la democracia en el ámbito local y regional subestatal.

El detalle de esta propuesta nos muestra un proyecto mucho más ambicioso que el ejemplificado por el modelo 2, porque en cierto sentido intenta adaptar las instituciones del modelo de democracia territorial al ámbito internacional, creando una supraestructura institucional con gran poder para interferir en las políticas de los Estados (incluso superando lo que para muchos sería aceptable en el ámbito interno, como sus propuestas de intervención en la economía). Aquí sí tiene sentido plantearse cuáles deben ser las formas adecuadas de representación democrática, pero parece que el debate se da por cerrado al importarse el modelo parlamentario: representación electiva en una asamblea de los Estados, formas de participación externas mediante grupos de presión que operan en la sociedad civil, etc. Y resuelven el problema de la determinación de quiénes deben ser los sujetos en el ámbito internacional incluyendo junto a los Estados a toda una variedad de actores (ONGs, organizaciones regionales...) e incluso a los propios ciudadanos individuales. El poder ejecutivo principal quedaría en manos de los Estados, organizados en una estructura más igualitaria y con capacidad para hacer efectivas sus decisiones, y los ciudadanos tendrían una representación directa en una Asamblea mundial. La idea que debe guiar esta organización, como hemos dicho, es la descentralización del poder, desde lo local hasta lo mundial. Sin embargo, a diferencia de la perspectiva federalista, parece que esta concepción se construye de arriba hacia abajo, pues son las instituciones cosmopolitas las que establecen la legislación básica y los principios «universales» que condicionarán las decisiones de las instituciones pertenecientes a los niveles inferiores. Y una de las cuestiones que cabría plantearse es hasta qué punto los ciudadanos van a considerar esas instituciones cosmopolitas más legítimas (en el sentido de más representativas) que las estatales, con las que seguramente tendrán una mayor identificación.

Asimismo, igual que sucedía con las propuestas del modelo 2, se parte de la división radical entre sociedades democráticas y las que no lo son, quedando poco clara la forma en la que se va a combinar el modelo tradicional 
con el nuevo orden cosmopolita, salvo en una versión en la que los regímenes liberales (que ahora coinciden con los Estados más poderosos) utilicen su fuerza y recursos para imponerlo a los que no lo son.

Modelo 4: Como hemos dicho al comienzo, aquí incluiríamos propuestas mucho menos articuladas, cuyo rasgo común sería confiar en una democratización por la fuerza de los hechos que insiste en la descentralización del poder y la participación directa de los individuos.

Un ejemplo ilustrativo sería el cosmopolitismo doméstico o libertario de Echeverría (1996) que parte de una base individualista, pues son los ciudadanos cosmopolitas los que se asocian libremente entre sí trascendiendo las formas territoriales de las que dependen la existencia y las constituciones de los Estados. La globalización, con todas las transformaciones que lleva consigo, proporcionaría los fundamentos de una nueva forma de organización social: telépolis, constituida por redes de ciudadanos que han creado una sociedad civil desterritorializada. Este tipo de organización otorgaría una nueva primacía a lo doméstico y haría surgir un nuevo espacio público, basado en los medios de comunicación, que impulsaría la pluralidad y permitiría un mayor control de la calidad del político. Y la fuerza cohesionante de este nuevo tipo de sociedad sería el mercado.

Junto a esta versión un tanto «utópica», dentro de esta categoría que reconoce la importancia de la dimensión internacional podríamos situar la propuesta de «demarquía» (Burnheim, 1986) que desconfía de la creación de una estructura estatal mundial que pudiera ser manipulable por las superpotencias y que, por ello, difícilmente sería democrática. Este proyecto propugna un nuevo tipo de democracia no territorial, sino que represente intereses, porque lo que sí es cierto es que existe la necesidad de que se creen autoridades específicas que traten problemas concretos (solución de problemas técnicos y desarrollo económico y social). En esta «demarquía» (demarchy) cada ciudadano tendría voto en proporción a su interés material en cada área de decisión concreta y la forma de organizar la representación sería tomando una muestra específica de la población que funcionaría como un comité.

Esto es algo similar a lo que viene a decir Roseneau (1998). En el contexto de la nueva sociedad mundial que ha generado esa nueva gobernación sin gobierno identificada con la existencia de un gran número de sistemas legales que han producido un gran poder colectivo enormemente desagregado sí sería posible encontrar ámbitos de coherencia que operan en diferentes lugares y niveles y que podrían definir los trazos de lo que podría ser esa gobernación en el futuro.

No obstante, al plantear en este contexto de qué modo sería posible preservar y extender la democracia se enfatiza que hay que evitar propuestas que se midan con el modelo aplicable a una base territorial determinada. Conceptos como rendición de cuentas y representación deberían, por el contrario, encontrar un equivalente funcional para el espacio globalizado. Y estos 
equivalentes, en opinión de Roseneau, podrían estar ya esbozados: la propia disgregación que caracteriza a este sistema contribuye a la descentralización del poder e impide la aparición de gobiernos mundiales autocráticos; los sistemas legales no tienen control fuera del ámbito de su jurisdicción y su alcance es limitado, lo que evita la concentración de centros de poder; la creciente expansión de ONGs desempeña un papel similar al que en las democracias territoriales realizaban los controles de los electores, el legislativo sobre el ejecutivo y la prensa (crítica y publicidad); los nuevos movimientos sociales aparecidos para defender causas concretas contribuyen al establecimiento y profundización de los lazos sociales facilitados por las nuevas tecnologías; las alianzas de ciudades y regiones generan nuevas identidades que superan los límites territoriales y pueden servir de contrapeso al poder de los Estados (o colaborar con ellos); y las nuevas tecnologías contienen también un potencial democrático que contribuye a la creación de redes que agrupan intereses, proporcionan información no controlada y crean comunidades de personas que comparten ideas e intereses sin base territorial. Junto a estos sistemas de control se podrían señalar otros no formalizados pero que contribuyen a un control público: reputación, autoridad moral, protestas organizadas, coaliciones de organizaciones gubernamentales o no, boicots, etc... El resultado, según dicho autor, es que las tendencias mundiales que conducen a la disgregación y al localismo a la vez pueden ser atenuadas por otras no menos poderosas que conducen a la agregación y la globalización, mostrando un complejo sistema de constreñimientos que pueden jugar un papel similar al de las prácticas democráticas.

En estos modelos que hemos incluido en la cuarta categoría, se enfatizarían dos elementos característicos de la democracia: la participación en la sociedad civil y la rendición de cuentas como instrumentos de control del poder y garantía de que va a tener en cuenta en su actuación los intereses de los ciudadanos. Y queda desdibujada la concepción de representación como mecanismo para satisfacer el ideal democrático de identificación entre gobernantes y gobernados (democracia como «gobierno del pueblo»), haciendo compatible la división del trabajo y el principio de igualdad democrática (Manin, 1997:130). No se trataría de crear nuevos centros de poder institucionales que reproduzcan en un nivel superior los ya existentes en los Estados, sino de reforzar su control por parte de los ciudadanos.

La pluralidad de propuestas normativas sobre las posibilidades de democratización del orden internacional, o incluso de su conveniencia, es muestra de la falta de un consenso claro sobre cómo debería proyectarse la idea de democracia a un ámbito diferente del de la comunidad política con base territorial y con una identidad definida. Las sospechas arrojadas sobre el «democentrismo» (Del Águila, 2000) empeñado en la constitución de un poder internacional que asegure las formas políticas necesarias para la forma de vida occidental, dejan al descubierto la diversidad de intereses que están detrás 
de la mayoría de los conflictos políticos y la dificultad de que encuentren acomodo en un sistema constituido por sujetos (los Estados) que detentan un poder muy desigual. Por ello, a pesar de que lo normativo trasciende las posibilidades que en determinado momento ofrece la realidad, parece que la base de la representación internacional seguirá estando constituida durante bastante tiempo por los Estados, con lo que el objetivo fundamental a corto plazo sería la instauración de un «rule of law» mínimo que asegure la convivencia pacífica. La subsanación del «déficit de legitimidad democrática» que están experimentando los Estados debido a la globalización se basaría más en la exigencia de presencia (y su control interno, una vez allí) de representantes de los Estados en las nuevas instancias de decisión. El desarrollo de una sociedad civil mundial que proporcione fuentes de información alternativas, haga públicos los conflictos y fiscalice las actuaciones de gobiernos siempre será algo positivo, pero no parece que deba ser la única depositaria de las esperanzas de una mejor convivencia mundial.

\section{BIBLIOGRAFÍA}

Archibugi, D. (1998): «Principles of Cosmopolitan Democracy», en Archibugi, D.; Held , D., y Köhler, Martin (eds.) (1998): Re-imagining Political Community, Cambridge, Polity Press.

Archibugi, D., y Held, D. (eds.) (1995): Cosmopolitan Democracy. An Agenda for the New World Order, Cambridge, Polity Press.

Archibugi, D.; Held, D., y KöHler, Martin (eds.) (1998): Re-imagining Political Community, Cambridge, Polity Press.

BECK, U. (1998): ¿Qué es la globalización?, Barcelona, Paidós.

Beetham, D. (1998): «Human Rights as a Model for Cosmopolitan Democracy», en Archibugi, D.; Held, D., y KöHler, Martin (1998): Re-imagining Political Community, Cambridge, Polity Press.

Bozeman, A. (1984): «The International Order in a Multicultural World», en Bull, H., y Watson, A. (eds.): The Expansion of International Society, Oxford, Oxford University Press.

Burnheim, J. (1986): «Democracy, Nation-states and World system», en Held, D., y Pollit (eds.): New Forms of Democracy, Londres, Sage.

Crawford, J., y Marks, S. (1998): «The global Democracy Deficit. An essay in International Law and its Limits», en Archibugi, D.; Held, D., y Köhler, Martin (1998): Re-imagining Political Community, Cambridge, Polity Press.

ECheverría, J. (1996): "Cosmopolitas domésticos a finales del siglo xx», en Aramayo, Muguerza y Roldán (eds.): La paz y el ideal cosmopolita de la Ilustración, Madrid, Tecnos.

Del Águila, R. (2000): La senda del mal. Política y razón de Estado, Madrid, Taurus. Held, D. (1997): La democracia y el orden global, Barcelona, Paidós.

KANT, I. (1985): Sobre la paz perpetua, Madrid, Tecnos.

Manin, B. (1997): The principles of representative government, Cambridge, Cambridge University Press. 
RAwls, J. (1997): «El derecho de gentes», en Isegoría, núm. 16, pp. 5-36.

Roseneau, J. (1998): «Governance and Democracy in a Globalizing World», en ARchIBugi, D.; Held, D., y KöHler, Martin (1998): Re-imagining Political Community, Cambridge, Polity Press.

Zolo, D. (2000): Cosmópolis. Perspectiva y riesgos de un gobierno mundial, Barcelona, Paidós. 